\title{
Analytical Solution of Tunnel Surrounding Rock for Stress and Displacement Based on Lade-Duncan Criterion
}

\author{
MingZheng Zhu $\mathbb{D}^{1},{ }^{1}$ Yugui Yang $\mathbb{D}^{1,2}$ Feng Gao $\mathbb{D}^{1,2}$ and Juan Liu ${ }^{1}$ \\ ${ }^{1}$ School of Mechanics and Civil Engineering, China University of Mining and Technology, Xuzhou 221116, China \\ ${ }^{2}$ State Key Laboratory for Geomechanics and Deep Underground Engineering, China University of Mining and Technology, \\ Xuzhou 221116, China \\ Correspondence should be addressed to Yugui Yang; ygyang2009@126.com
}

Received 7 November 2017; Accepted 10 April 2018; Published 14 May 2018

Academic Editor: Cumaraswamy Vipulanandan

Copyright (c) 2018 MingZheng Zhu et al. This is an open access article distributed under the Creative Commons Attribution License, which permits unrestricted use, distribution, and reproduction in any medium, provided the original work is properly cited.

\begin{abstract}
The deformation and failure of tunnel surrounding rock is the result of tunnel excavation disturbance and rock stress release. When the local stress of surrounding rock exceeds the elastic limit of rock mass, the plastic analysis of surrounding rock must be carried out to judge the stability of tunnel. In this study, the Lade-Duncan yield criterion is used to calculate the analytic solutions for the surrounding rock in a tunnel, and the radius and displacement of the plastic zone are deduced using an equilibrium equation. The plastic zone radius and displacement based on Lade-Duncan criterion and Mohr-Coulomb criterion were compared by using single-factor analysis method under the different internal friction angles, in situ stresses, and support resistances. The results show that the solutions of the radius and displacement of plastic zone calculated by the Lade-Duncan criterion are close to those of Mohr-Coulomb criterion under the high internal friction angle and support resistance or low in situ rock stress; however, the radius and displacement of the plastic zone calculated by the Lade-Duncan criterion are larger under normal circumstances, and the Lade-Duncan criterion is more applicable to the stability analysis of the surrounding rock in a tunnel.
\end{abstract}

\section{Introduction}

The original equilibrium state of stress is disrupted due to the excavation of underground engineering, which causes the stress to be redistributed [1-3]. We know that the deformation of surrounding rock is the result of excavation disturbance and stress release. Before the tunnel excavation, the rock mass is in the stress equilibrium state. After excavation, the stress of surrounding rock will redistribute greatly, the radial stress around the tunnel will decrease to zero, the strength of surrounding rock will decrease obviously, and then the tangential stress concentration will appear. Generally, the surrounding rock around the tunnel will crack first and gradually develop into the deep zone, forming a fracture zone and a plastic zone, while the deeper rock is still in an elastic state, which is called the elastic zone. When the local stress of surrounding rock exceeds the elastic limit of rock mass and enters the plastic state, the elastoplastic analysis of surrounding rock is necessary to provide the reference for design of tunnel support. The size of plastic zone and stress distribution of tunnel surrounding rock are very important to the design of tunnel support [4].

The design of excavation and support based on a proper strength criterion could not only reasonably reflect the mechanical properties of the rock, but also bring huge economic benefit to the construction of rock engineering. Many failure criteria have been proposed to the elastoplastic analysis of the surrounding rock in a tunnel such as the Mohr-Coulomb strength criterion [5-7], Hoek-Brown strength criterion [8-10], and the unified strength theory, which considers the effect of intermediate principal stress [11-15]. The studies show that the intermediate principal stress has significant effects on surrounding rock stress distribution, plastic zone radius, and displacement. However, 
Mohr-Coulomb criterion and Hoek-Brown criterion ignored the effects of intermediate principal stress on rock mass strength, which led to unfavorable results for engineering applications. Although the unified strength theory can reflect intermediate principal stress, the expression of this criterion is complex, and parameters are difficult to be measured in the surrounding rock of the actual roadway.

One of the most attractive of all the alternative failure criteria is the Lade-Duncan failure criterion [16], which has been widely used in geotechnical engineering. In this study, the Lade-Duncan strength theory is used to carry out the analysis of roadway surrounding rock. The plastic zone radius and displacement based on Lade-Duncan criterion and Mohr-Coulomb criterion were analyzed and compared by using single factor analysis method according to the different support resistances, internal friction angles and in situ stress.

\section{Description of the Lade-Duncan Criterion}

The Mohr-Coulomb criterion cannot reflect the effect of intermediate principal stress on damage and the yield characteristics caused by pure hydrostatic pressure. Its yield surface is a hexagonal pyramid with apex in the principal stress space. Once the stress point lies at the ridge or cone top, it will cause difficulties in mathematical processing. In 1975, Lade and Duncan proposed the Lade-Duncan failure criterion based on the results of triaxial strength failure tests of sand. After that, the yield surface function was improved by Lade $[17,18]$. When a spherical yield surface is added to the triangular cone of the open curved edge, it becomes a hat-type model, which is a concentric similar curved triangle on the plane of the stress space as shown in Figure 1. The Lade surface gives a smooth approximation to the Mohr-Coulomb surface [19]. Because of its smooth surface, the Lade-Duncan failure criterion is becoming more and more popular. The Lade-Duncan model can not only consider the influence of intermediate principal stress, but also has simple form. So it is easy to be applied in engineering. Lade-Duncan strength criterion is expressed as

$$
\frac{I_{1}^{3}}{I_{3}}=k=\frac{(3-\sin \varphi)^{3}}{(1+\sin \varphi)(1-\sin \varphi)^{2}},
$$

where $k$ is the material constant, $\varphi$ is the internal friction angle, and $I_{1}$ and $I_{3}$ are the first and third stress tensor invariants.

$$
\begin{aligned}
& I_{1}=\sigma_{1}+\sigma_{2}+\sigma_{3}, \\
& I_{3}=\sigma_{1} \sigma_{2} \sigma_{3},
\end{aligned}
$$

where $\sigma_{1}, \sigma_{2}$, and $\sigma_{3}$ are the principal stresses.

\section{Stability Analysis of Tunnel Surrounding Rock}

3.1. Mechanical Model and Basic Assumptions. Rock mass is a kind of material with complex structure, so it is difficult to describe its mechanical behavior with specific constitutive equation. In order to carry out the elastoplastic analysis of

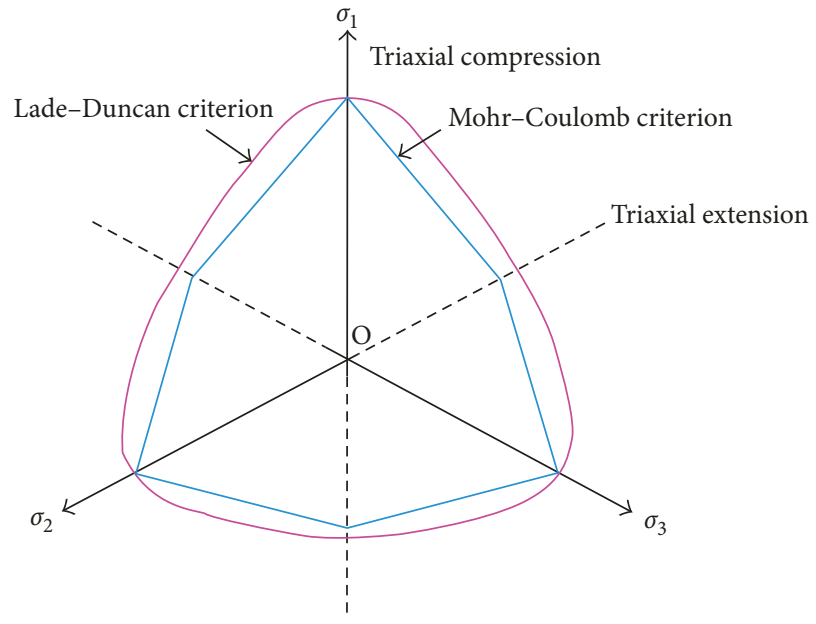

Figure 1: The Mohr-Coulomb and Lade-Duncan failure surfaces in the $\pi$-plane.

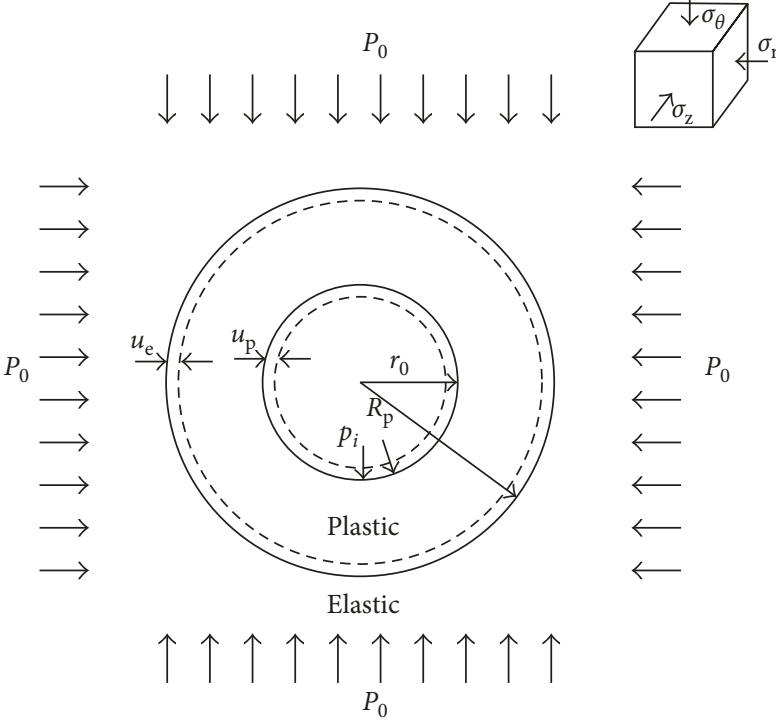

FIgURE 2: Calculation model of tunnel surrounding rock.

surrounding rock mass, the following assumptions are made:

(1) Rock mass is a continuous, homogeneous, and isotropic elastoplastic material.

(2) The section of the tunnel is circular and the length is infinite, so it can be simplified as plane strain problem.

(3) Ignoring the effects of the surrounding rock weight on the yield, the original rock stress can be simplified as a uniform stress distribution. So the tunnel is under the conditions of uniform stress $p_{0}$ and support resistance $p_{i}$.

(4) The radius of plastic zone produced by tunnel excavation is $R_{\mathrm{p}}$.

Based on the above assumption, the problem can be simplified as the mechanical model as shown in Figure 2. 
3.2. Stress Analysis of Tunnel Surrounding Rock. The radial stress $\sigma_{\mathrm{r}}$, tangential stress $\sigma_{\theta}$, and axial stress $\sigma_{\mathrm{z}}$ of tunnel are orthogonal to each other. When the lateral pressure coefficient $\lambda=1$, the stresses $\sigma_{\mathrm{r}}, \sigma_{\theta}$, and $\sigma_{\mathrm{z}}$ can be regarded as three principal stresses. If the body strain $\varepsilon_{\mathrm{v}}$ of the surrounding rock in the plastic zone is zero, we know that the relationship of stresses is satisfied: $\sigma_{\theta p}>\sigma_{\mathrm{zp}}>\sigma_{\mathrm{rp}}$ (where $\mathrm{p}$ stands for the stress component of the plastic zone) and

$$
\sigma_{\mathrm{zp}}=\frac{1}{2}\left(\sigma_{\mathrm{rp}}+\sigma_{\theta \mathrm{p}}\right)
$$

We see that the three principal stresses in plastic zone are $\sigma_{1}=\sigma_{\theta \mathrm{p}}, \sigma_{2}=\sigma_{\mathrm{zp}}$, and $\sigma_{3}=\sigma_{\mathrm{rp}}$. According to (1), we have

$$
\left(\sigma_{\mathrm{rp}}+\sigma_{\theta \mathrm{p}}+\sigma_{\mathrm{zp}}\right)^{3}-k\left(\sigma_{\theta \mathrm{p}} \sigma_{\mathrm{rp}} \sigma_{\mathrm{zp}}\right)=0 \text {. }
$$

Substituting (3) in (4), we can get the relationship between $\sigma_{\theta \mathrm{p}}$ and $\sigma_{\mathrm{rp}}$ as follows:

$$
\sigma_{\theta \mathrm{p}}=\sigma_{\mathrm{rp}}+2 \sqrt{\frac{k-27}{27}} \sqrt{\sigma_{\theta \mathrm{p}} \sigma_{\mathrm{rp}}}
$$

3.3. Basic Equilibrium Differential Equation. In the elastic and plastic zone, the equilibrium differential equation can be written as

$$
\frac{d \sigma_{\mathrm{r}}}{d r}+\frac{\sigma_{\mathrm{r}}-\sigma_{\theta}}{r}=0
$$

and the geometric equation is expressed as follows:

$$
\begin{gathered}
\varepsilon_{\mathrm{r}}=\frac{d u}{d r}, \\
\varepsilon_{\theta}=\frac{u}{r},
\end{gathered}
$$

where $u$ is the radial displacement; and $r$ is the radius of the excavation.

3.4. Stress Solutions of the Elastic Zone. The stress of the elastic zone of the surrounding rock can be obtained by the axisymmetric plane strain problem. The equations can be obtained as follows:

$$
\begin{aligned}
& \sigma_{\mathrm{re}}=p_{0}\left(1-\frac{R_{\mathrm{p}}^{2}}{r^{2}}\right)+\sigma_{\mathrm{R}} \frac{R_{\mathrm{p}}^{2}}{r^{2}}, \\
& \sigma_{\theta \mathrm{e}}=p_{0}\left(1+\frac{R_{\mathrm{p}}^{2}}{r^{2}}\right)-\sigma_{\mathrm{R}} \frac{R_{\mathrm{p}}^{2}}{r^{2}},
\end{aligned}
$$

where $\sigma_{\mathrm{R}}$ is the radial stress on the interface between the elastic and plastic zones and e stands for the stress component of elastic zone.

3.5. Stress Solutions of the Plastic Zone. Substituting (5) in (6), then we can get

$$
\ln r+c_{0}=b \sqrt{\frac{\sigma_{\mathrm{r}}}{\sigma_{\theta}}}
$$

where $b=\sqrt{(27 /(k-27))}, c_{0}$ is an integration constant.
Introducing the boundary conditions $r=r_{0}$ and $\sigma_{\mathrm{r}}=p_{i}$ in (5) and (9), $c_{0}$ can be obtained as follows:

$$
c_{0}=\sqrt{b^{2}+1}-\ln r_{0}-1,
$$

where $b=\sqrt{(27 /(k-27))}$.

From (5), (6), (9), and (10), the stress condition of the plastic zone can be expressed as follows:

$$
\begin{aligned}
& \sigma_{\mathrm{rp}}=\frac{p_{i}}{(\sqrt{(k /(k-27))})^{2}}\left(\ln \frac{r}{r_{0}}+\sqrt{\frac{k}{k-27}}-1\right)^{2}, \\
& \sigma_{\theta \mathrm{p}}=\frac{p_{i}}{(\sqrt{(k /(k-27))})^{2}}\left[\left(\ln \frac{r}{r_{0}}+\sqrt{\frac{k}{k-27}}\right)^{2}-1\right] .
\end{aligned}
$$

3.6. Radius of the Plastic Zone. The stress state at the radius of the plastic zone satisfies both the plastic stress condition and the elastic stress condition. We have $\sigma_{\mathrm{rp}}=\sigma_{\mathrm{re}}=\sigma_{\mathrm{R}}$ and $\sigma_{\theta \mathrm{p}}=\sigma_{\theta \mathrm{e}}$. From (8), we can obtain the following condition:

$$
\left.\left(\sigma_{\theta \mathrm{e}}+\sigma_{\mathrm{re}}\right)\right|_{r=R_{\mathrm{p}}}=\left.\left(\sigma_{\theta \mathrm{p}}+\sigma_{\mathrm{rp}}\right)\right|_{r=R_{\mathrm{p}}}=2 p_{0} .
$$

Introducing (12) in (11), we obtain the radius of the plastic zone as follows:

$$
\begin{aligned}
& \left(\ln \frac{R_{\mathrm{p}}}{r_{0}}+\sqrt{\frac{k}{k-27}}\right)\left(\ln \frac{R_{\mathrm{p}}}{r_{0}}+\sqrt{\frac{k}{k-27}}-1\right) \\
& -\frac{p_{0}(\sqrt{(k /(k-27))}-1)^{2}}{p_{i}}=0 .
\end{aligned}
$$

With the first term of (11), the radial stress on the elastoplastic interface can be obtained as follows:

$$
\sigma_{\mathrm{R}}=\frac{p_{i}}{(\sqrt{(k /(k-27))}-1)^{2}}\left(\ln \frac{R_{\mathrm{p}}}{r_{0}}+\sqrt{\frac{k}{k-27}}-1\right)^{2} .
$$

3.7. Displacement of Plastic Zone. According to the theory of literature [2], the elastic zone deformation can be treated as a thick wall cylinder, which has the infinite of the outside boundary radius, and the inner boundary radius is the plastic radius of $R_{\mathrm{p}}$. The radial displacement component $u_{\mathrm{e}}$ of tunnel surrounding rock in the elastic zone can be expressed as follows:

$$
u_{\mathrm{e}}=\frac{\left(p_{0}-\sigma_{\mathrm{R}}\right) R_{\mathrm{p}}}{2 G}
$$

where $G=E /(2(1+\mu)) ; E$ is the modulus of elasticity, and $\mu$ is the Poisson ratio.

Since the volume of the tunnel rock in the plastic zone can be assumed as constant, we can set up the following equation:

$$
R_{\mathrm{p}}^{2}-\left(R_{\mathrm{p}}-u_{\mathrm{e}}\right)^{2}=r_{0}^{2}-\left(r_{0}-u_{\mathrm{p}}\right)^{2} .
$$

According to (16), we have 


$$
u_{\mathrm{p}}=\frac{R_{\mathrm{p}}}{r_{0}} u_{\mathrm{e}} .
$$

From (14), (15), and (17), the following equation can be obtained:

$u_{\mathrm{p}}=\frac{R_{\mathrm{p}}^{2}}{2 r_{0} G}\left[p_{0}-\frac{p_{i}}{(\sqrt{(k /(k-27))}-1)^{2}}\left(\ln \frac{R_{\mathrm{p}}}{r_{0}}+\sqrt{\frac{k}{k-27}}-1\right)^{2}\right]$.

\section{Compared with the Mohr-Coulomb Criterion in Engineering Application}

In the reference example, a tunnel is excavated in limestone with different rock masses, which is $H=200 \mathrm{~m}$ in buried depth. The radius of the tunnel is $r_{0}=4 \mathrm{~m}$, the properties of the intact rock are $\sigma_{\mathrm{ci}}=50.0 \mathrm{MPa}, m_{i}=8$, GSI $=25$, and $D=0.6$. The rock bulk density is $\gamma=0.027 \mathrm{KN} / \mathrm{m}^{3}$, so the in situ rock stress is $p_{0}=\gamma H=5.4 \mathrm{MPa}$. The physical and mechanical parameters of the surrounding rock are $G=3.0 \mathrm{GPa}=, c=0.36 \mathrm{MPa}, p_{i}=1 \mathrm{MPa}$, and $\varphi=22^{\circ}$. The parameters $G, c$, and $\varphi$ are shear modulus, cohesion, and internal friction angle of rock mass, respectively [20-22].

4.1. Comparison of Plastic Zone Radius. In order to better analyze the solution of plastic zone radius $R_{p}$ computed by Lade-Duncan criterion in this study, the prediction is compared with the results computed by the Mohr-Coulomb criterion. According to the literature [21], the equation of plastic radius derived from Mohr-Coulomb criterion is as follows:

$$
R_{\mathrm{p}}=r_{0}\left[\frac{p_{0}+c \cdot \cot \varphi}{p_{i}+c \cdot \cot \varphi}(1-\sin \varphi)\right]^{(1-\sin \varphi) /(2 \sin \varphi)} .
$$

Single-factor analysis is used to consider the influence of internal friction angle $\varphi$, in situ rock stress $p_{0}$, and support resistance $p_{i}$ on the radius of plastic zone of surrounding rock. Referring to related literature and experimental data, the range of rock internal friction angle $\varphi$ in this paper is $18^{\circ} \sim 32^{\circ}$, the in situ rock stress $p_{0}$ is $2 \sim 8 \mathrm{MPa}$, and the supporting resistance $p_{i}$ is $0.6 \sim 2.0 \mathrm{MPa}$. When considering the influence of the variation of the internal friction angle on the radius of the plastic zone, we let the original rock stress $p_{0}=5.4 \mathrm{MPa}$ and the support resistance $p_{i}=1 \mathrm{MPa}$. When considering the influence of the variation of the in situ stress on the radius of the plastic zone, we let the internal friction angle $\varphi=22^{\circ}$ and the support resistance $p_{i}=1 \mathrm{MPa}$. When considering the influence of the support resistance on the radius of the plastic zone, we let the internal friction angle $\varphi=22^{\circ}$ and the original rock stress $p_{0}=5.4 \mathrm{MPa}$.

As shown in Figures 3 and 4 , the plastic radius $R_{\mathrm{p}}$ decreases as the internal friction angle $\varphi$ and the supporting resistance $p_{i}$ increase. According to Figure 5, plastic radius $R_{\mathrm{p}}$ increases as the in situ stress $p_{0}$ increases. From comparison, it is found that the growth rate of the Lade-Duncan criterion solution is larger than the solution of the Mohr-

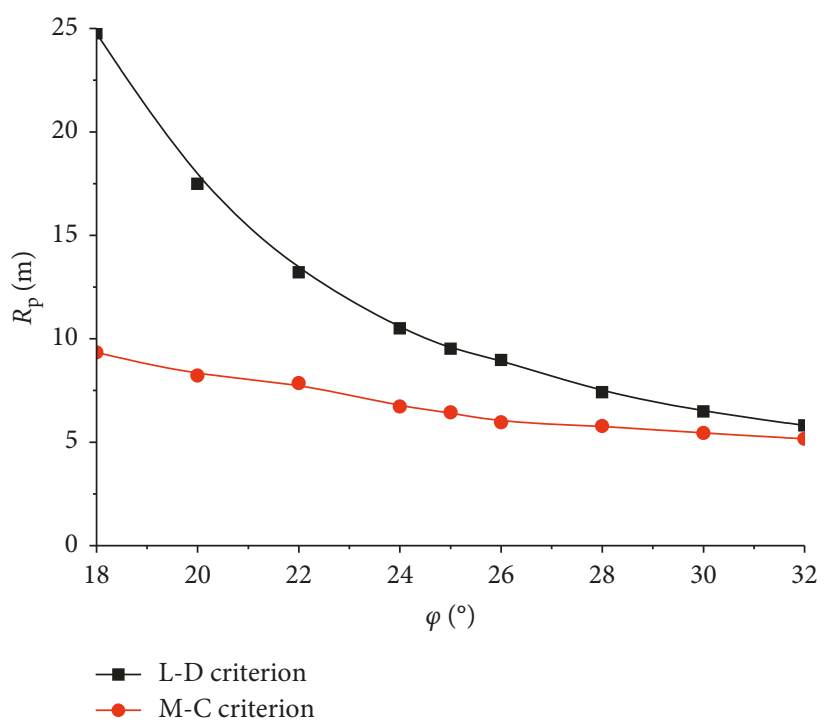

FIgURE 3: Relation curves between internal friction angle and plastic zone radius.

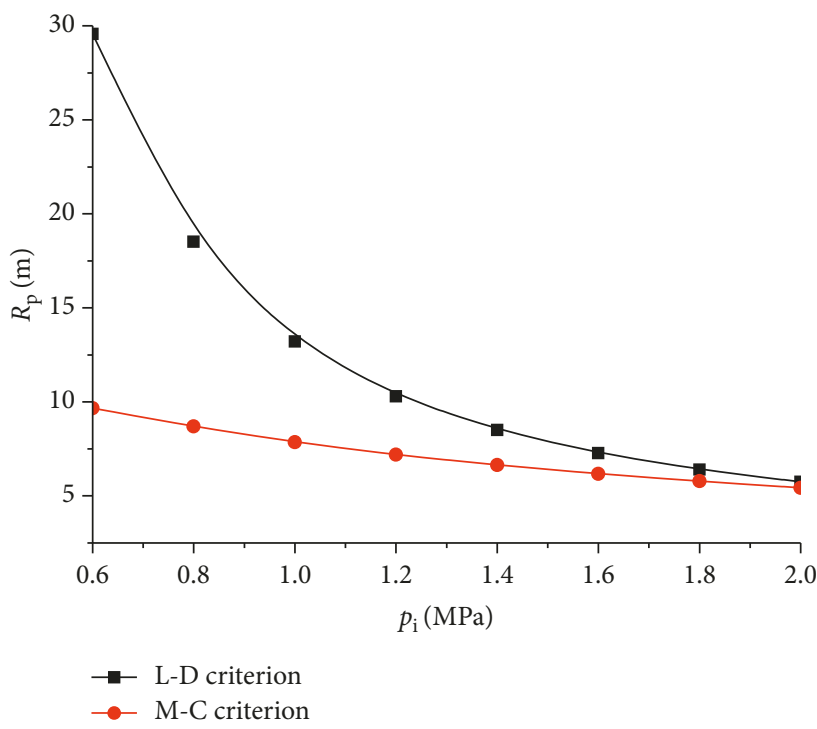

Figure 4: Relation curves between support resistance and plastic zone radius.

Coulomb criterion, and also we note that the radius of the plastic zone obtained by the Lade-Duncan criterion is gradually larger as the $p_{0}$ increases. As we know, the increase of $p_{0}$ means the increase of the buried depth, that is to say, when the tunnel is too deep, the $R_{\mathrm{p}}$ obtained by the Lade-Duncan criterion will tend to be larger. We can also find that the variation tendency of the two yield criteria is the same. The results show that the solution of the Lade-Duncan criterion is larger than the solution of the Mohr-Coulomb criterion. As we all know, the empirical range of rock mechanics for the radius of plastic zone after tunneling is $3 \sim 5 r_{0}$, which in this paper is $12 \sim 20 \mathrm{~m}$. So we can see that the radius of plastic zone obtained by Lade-Duncan criterion is much closer to the empirical range of rock mechanics. The radius of plastic zone obtained by Mohr-Coulomb 


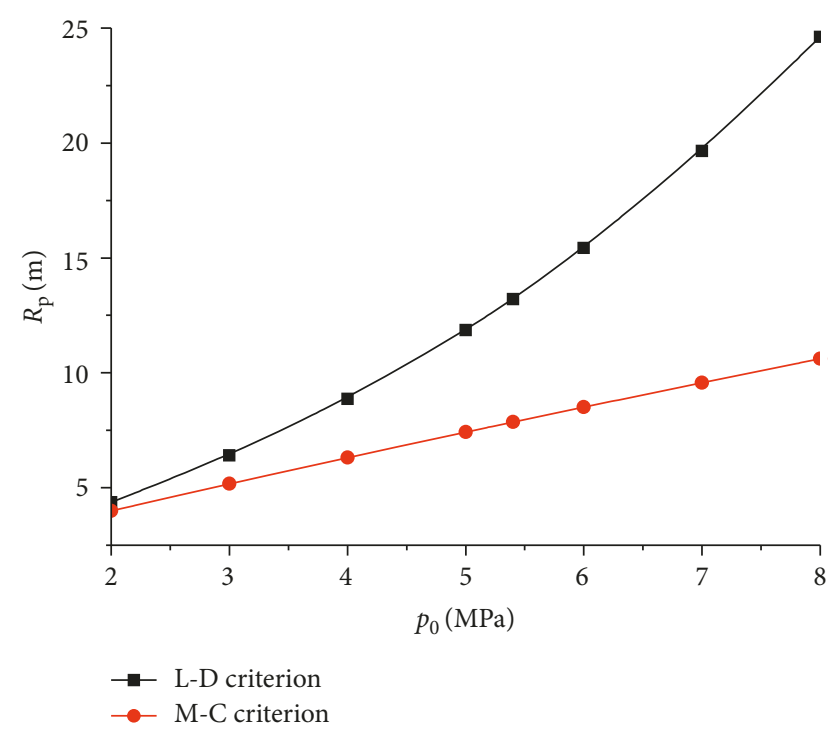

Figure 5: Relation curves between in situ stress and plastic zone radius.

criterion is too small, which may lead to danger in engineering application. It is because that the Mohr-Coulomb criterion completely ignores the influence of the intermediate principal stress on the deformation of tunnel surrounding rock, but the Lade-Duncan criterion takes into account the influence of the intermediate principal stress.

4.2. Comparison of Plastic Zone Displacement. Due to the effect of in situ rock stress, the deformation and displacement will appear around the tunnel, and the plastic zone, which is harmful to the stability of surrounding rock, will gradually develop. In the following content, we compare the displacement of the plastic zone of tunnel surrounding rock obtained by the Lade-Duncan criterion and the MohrCoulomb criterion. According to the literature [21], the equation of plastic zone displacement derived from Mohr-Coulomb criterion is as follows:

$$
u_{\mathrm{p}}=\frac{R_{\mathrm{p}}^{2}\left(p_{0} \sin \varphi+\cos \varphi\right)}{2 r_{0} G} .
$$

Similar to the analysis of radius of plastic zone, we still use single factor method. When considering the influence of the internal friction angle on the displacement of the plastic zone, we let $p_{0}=5.4 \mathrm{MPa}$ and $p_{i}=1 \mathrm{MPa}$. When considering the influence of the variation of the internal friction angle on the displacement of the plastic zone, we let $\varphi=22^{\circ}$ and $p_{i}=1 \mathrm{MPa}$. When considering the influence of the variation of the internal friction angle on the displacement of the plastic zone, we let $\varphi=22^{\circ}$ and $p_{0}=5.4 \mathrm{MPa}$. The calculated results by two methods are shown in Figures 6 and 7 and Figure 8.

As shown in Figures 6 and 8, plastic zone displacement $u_{\mathrm{p}}$ decreases as the internal friction angle $\varphi$ and the supporting resistance $p_{i}$ increases. And it can be seen that with the increase of $\varphi$ and $p_{i}$, the $u_{\mathrm{p}}$ obtained by the LadeDuncan criterion and the Mohr-Coulomb criterion will

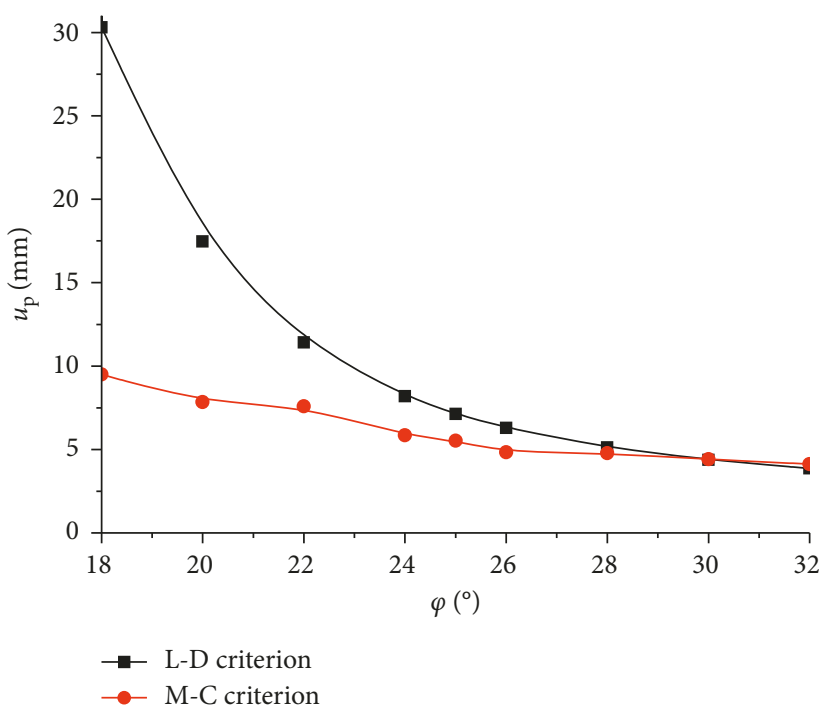

FIGURE 6: Relation curves between internal friction angle and plastic zone displacement.

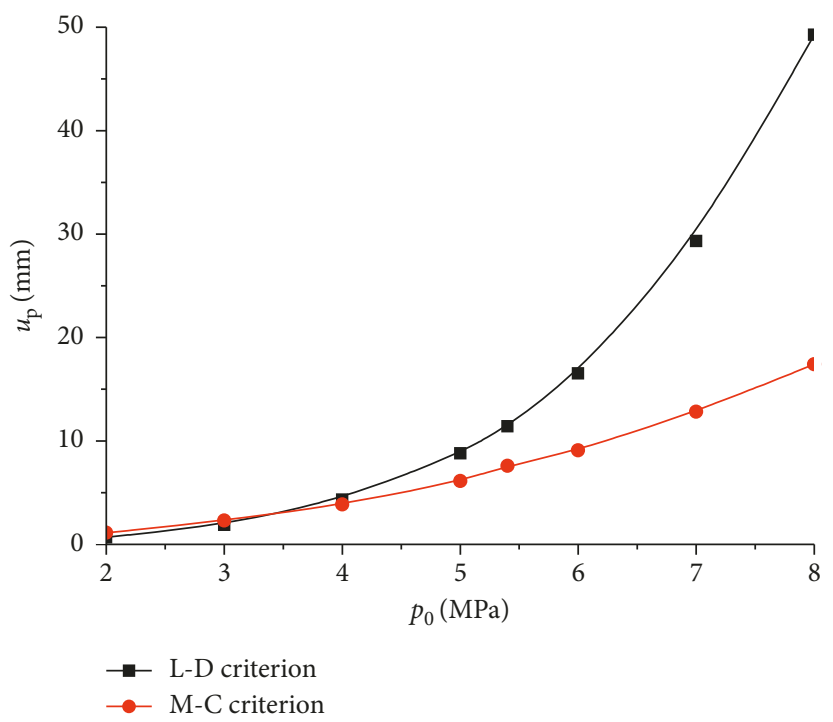

FIgURE 7: Relation curves between in situ stress and plastic zone displacement.

approach gradually. According to Figure 7, the plastic zone displacement $u_{\mathrm{p}}$ increases as the in situ stress $p_{0}$ increases. By comparison, we can find that the solution of the Lade-Duncan criterion is larger than the solution of the Mohr-Coulomb criterion. By analyzing the radius of plastic zone above, we can know that the plastic zone displacement of tunnel surrounding rock obtained by Mohr-Coulomb criterion is smaller in a certain range. The main reason for this result is that the Mohr-Coulomb criterion completely ignores the intermediate principal stress.

4.3. Stress Analysis of Tunnel Surrounding Rock. In order to better analyze the stress distribution in tunnel surrounding rock, we let the supporting resistance $p_{i}=1 \mathrm{MPa}$, the 


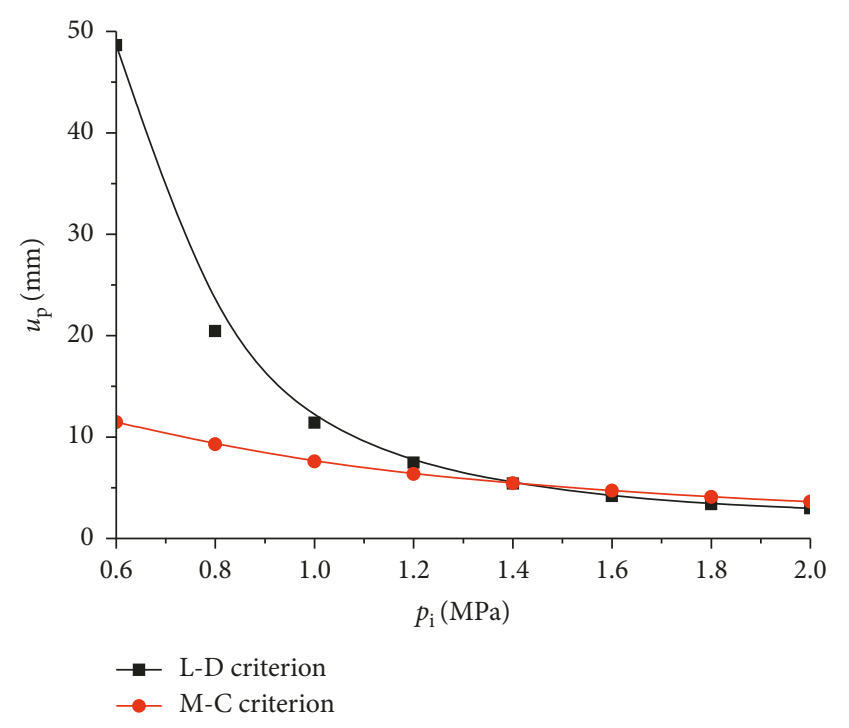

FIGURE 8: Relation curves between support resistance and plastic zone displacement.

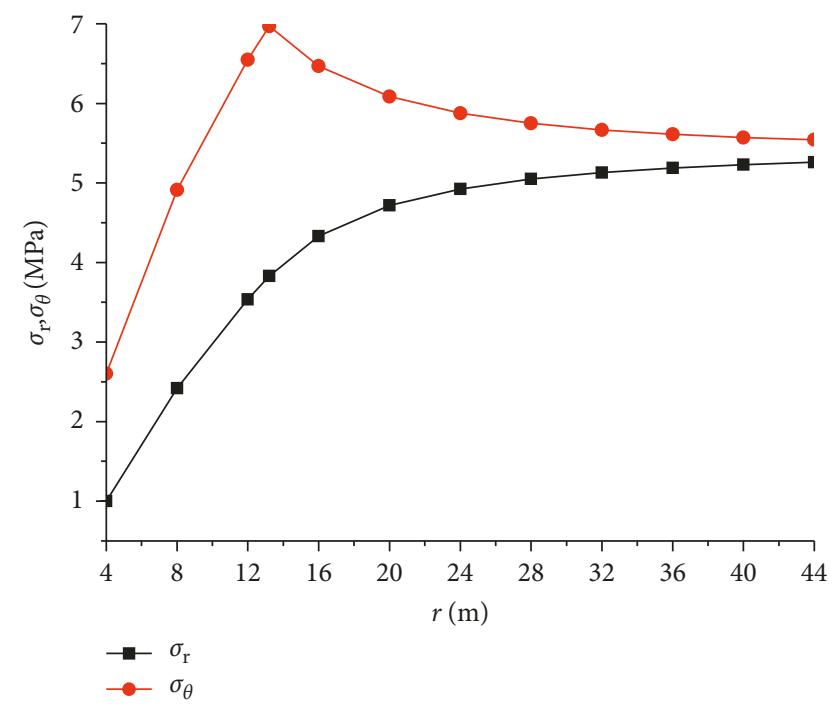

FIGURE 9: Stress distribution of the surrounding rock in the tunnel.

internal friction angle $\varphi=22^{\circ}$, the radius of the tunnel is $r_{0}=4 \mathrm{~m}$, and the in situ rock stress $p_{0}=5.4 \mathrm{MPa}$.

As shown in Figure 9, the radial stress and tangential stress increase with the increase of the radius, when the radius is equal to the plastic zone radius, and the tangential stress reaches a maximum and then begins to decline. After the radius is equal to the radius of the plastic zone, the radial stress increases continuously, but the rate of increase decreases gradually; finally both approach the values of the in situ rock stress.

\section{Conclusions}

The selection of yield criterion has a great influence on the stability analysis of the surrounding rock. Different yield criteria have different sensitivities to strength parameters, in situ rock stress, and support resistance of rock mass. In this study, the Lade-Duncan criterion is used to analyze the stability of surrounding rock of circular tunnel. The following conclusions can be obtained:

(1) The elastoplastic analysis of the surrounding rock of circular tunnel is carried out by combining the equilibrium equation and geometric equation. The expressions of elastoplastic stress, radius, and displacement of plastic zone based on the Lade-Duncan yield criterion are obtained.

(2) The comparisons of the radius of plastic zone and the law of stress distribution of tunnel surrounding rock calculated by using Lade-Duncan criterion and Mohr-Coulomb criterion are compared. The results show that they are approximately similar; however, the radius and displacement of the plastic zone under the Lade-Duncan criterion are larger than that of the Mohr-Coulomb criterion. It is because that the Lade-Duncan criterion takes the influence of intermediate principal stress into consideration.

(3) The radius of plastic zone and displacement solution of Lade-Duncan criterion is approximately close to Mohr-Coulomb criterion under the high internal friction angle and support resistance or low in situ rock stress. However, under normal circumstances, the solution of the Lade-Duncan criterion is closer to the engineering practice.

\section{Conflicts of Interest}

The authors declare that they have no conflicts of interest.

\section{Acknowledgments}

This research was supported by the National Natural Science Foundation of China (51574219); the State Key Research Development Program of China (2016YFC0600705); and the National Natural Science Foundation of China (51604263).

\section{References}

[1] Q. Feng and B. Jiang, "Analytical solution for stress and deformation of the mining floor based on integral transform," International Journal of Mining Science and Technology, vol. 25, no. 4, pp. 581-586, 2015.

[2] C. Jaeger, Rock Mechanics and Engineering, Cambridge University Press, London, UK, 1985.

[3] C. Li, J. H. Xu, J. Z. Pan, and C. Ma, "Plastic zone distribution laws and its types of surrounding rock in large-span roadway," International Journal of Mining Science and Technology, vol. 22, no. 1, pp. 23-28, 2012.

[4] Y. Zhang, B. Xing, and C. Song, "Numerical simulation of the rockburst mechanism in the meihuashan tunnel," Modern Tunnelling Technology, vol. 51, no. 1, pp. 97-104, 2014.

[5] J. C. Jaeger and N. G. W. Cook, Foundamentals of Rock Mechanics, Chapman and Hall Press, London, UK, 1978.

[6] Z. Qiang, S. Wang, and G. E. Xiurun, "Elastoplastic analysis of circular openings in strain-softening rock masses," Chinese Journal of Rock Mechanics and Engineering, vol. 29, no. 5, pp. 1031-1035, 2010, in Chinese. 
[7] X. F. Yu and Y. R. Zheng, Underground Engineering Rock Stability Analysis, China Coal Industry Publishing House Press, Beijing, China, 1983.

[8] W. R. Judd, Underground Excavations in Rock, The Institute of Mining and Metallurgy Press, Carlton, VIC, Australia, 1980.

[9] Q. Zeng, "Elasto-plastic analysis of stresses and displacements around a circular opening using the Hoek-Brown empirical criterion," Journal of Engineering Geology, vol. 15, no. 6, pp. 757-761, 2007.

[10] S. Wen and S. Q. Yang, "Study of deformations of surrounding rock of tunnel based on Hoek-Brown criterion," Rock and Soil Mechanics, vol. 32, no. 1, pp. 63-69, 2011.

[11] M. H. Yu, Twin Shear Theory and its Application, Science Press, Beijing, China, 1998, in Chinese.

[12] H. X. Rong and Y. M. Hong, "New tri-shear failure criterion and its application in elasto-plastic analysis for the wall rock of tunnel," Journal of China Coal Society, vol. 28, no. 4, pp. 389-393, 2003, in Chinese.

[13] K. H. Ceng, H. Y. Ju, G. J. Cheng, and C. G. Zhang, "Elasticplastic analytical solutions for surrounding rocks of tunnels and its engineering applications," Meitan Xuebao/journal of the China Coal Society, vol. 36, no. 5, pp. 752-755, 2011, in Chinese.

[14] L. W. Chen, J. B. Peng, F. Wen, and S. Ping, "Analysis of surrounding rock mass plastic zone of round tunnel under non-uniform stress field based on the unified strength theory," Journal of China Coal Society, vol. 32, no. 1, pp. 20-23, 2007, in Chinese.

[15] Q. Zhang, H. Y. Wang, S. L. Wang, G. E. Xiu-Run, and G. Shao, "Deterioration elasto-plastic analysis of cracked surrounding rocks based on unified strength theory," Journal of China Coal Society, vol. 35, no. 3, pp. 381-386, 2010, in Chinese.

[16] P. V. Lade and J. M. Duncan, "Elastoplastic stress-strain theory for cohesionless soil," Journal of the Geotechnical Engineering Division, vol. 101, no. 1, pp. 1037-1053, 1975.

[17] P. V. Lade, "Elastic-plastic stress-strain theory for cohesionless soil with curved yield surfaces," International Journal of Solids and Structures, vol. 13, no. 11, pp. 1019-1035, 1977.

[18] P. K. Woodward, "Earth pressure coefficients based on the Lade-duncan failure criterion," Engineering Structures, vol. 19, no. 9, pp. 733-737, 1997.

[19] S. L. Wang, Design of Underground Construction Structure, Tsinghua University Press, Beijing, China, 2009.

[20] Z. Y. Xu, Rock Mechanics, China Water Power Press, Beijing, China, 1993.

[21] X. Huang, J. Zhang, L. Yang, S. Yang, and X. Wang, "Elastoplastic analysis of the surrounding rock mass in circular tunnel based on the generalized nonlinear unified strength theory," International Journal of Mining Science and Technology, vol. 26, no. 5, pp. 819-823, 2016.

[22] Q. B. Zeng, E. Z. Wang, and S. J. Wang, "Comparison between plastic radius around a circular opening derived from HoekBrown failure criterion and calculated through modified fenner formula," Journal of Shenyang Jianzhu University Natural Science, vol. 24, no. 6, pp. 933-938, 2008. 


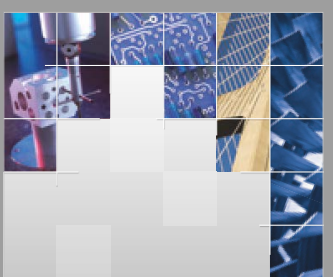

\section{Enfincering}
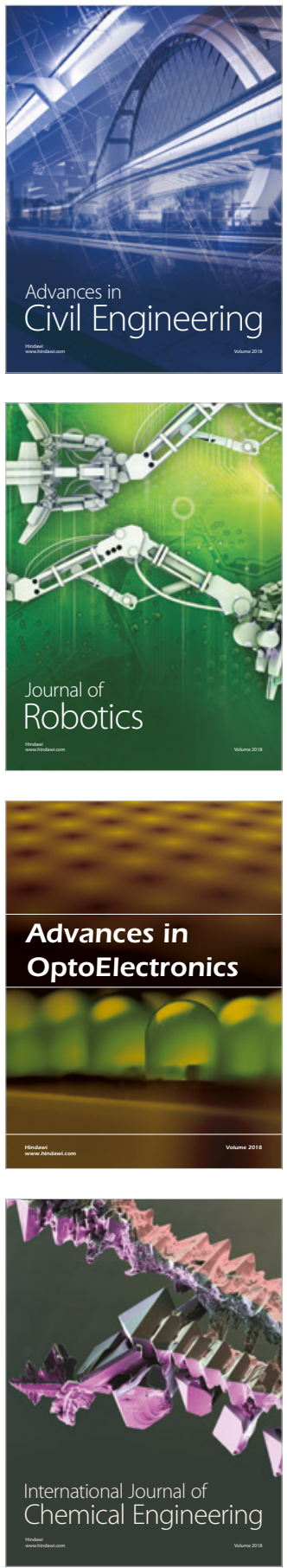

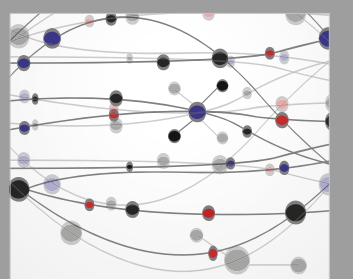

\section{Rotating \\ Machinery}

The Scientific World Journal

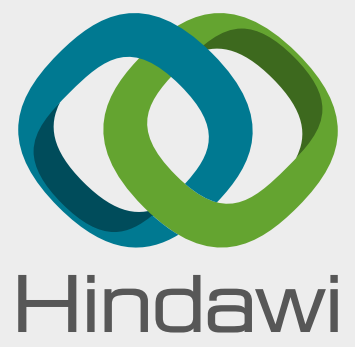

Submit your manuscripts at

www.hindawi.com
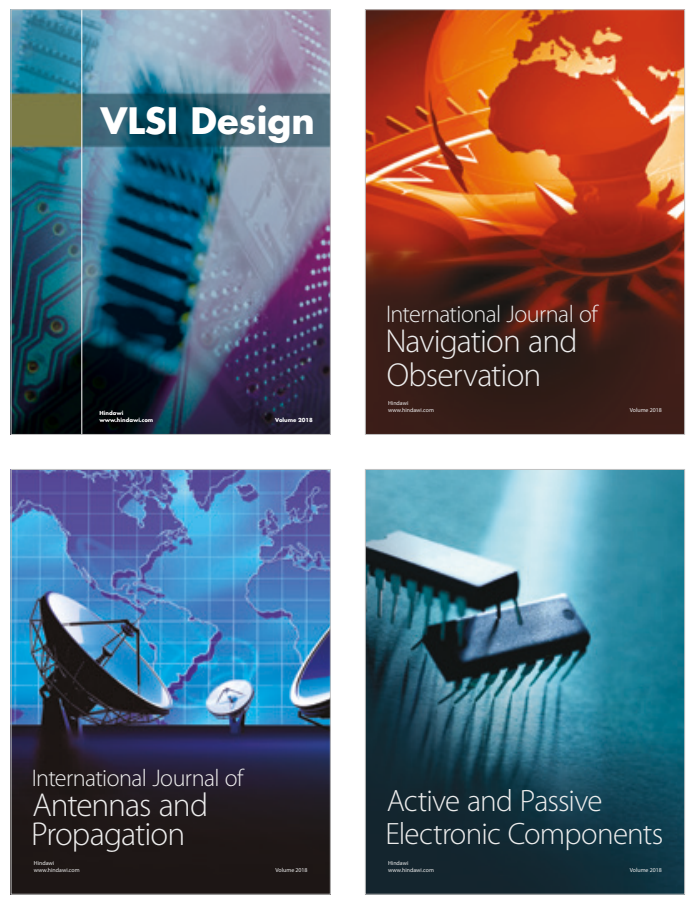
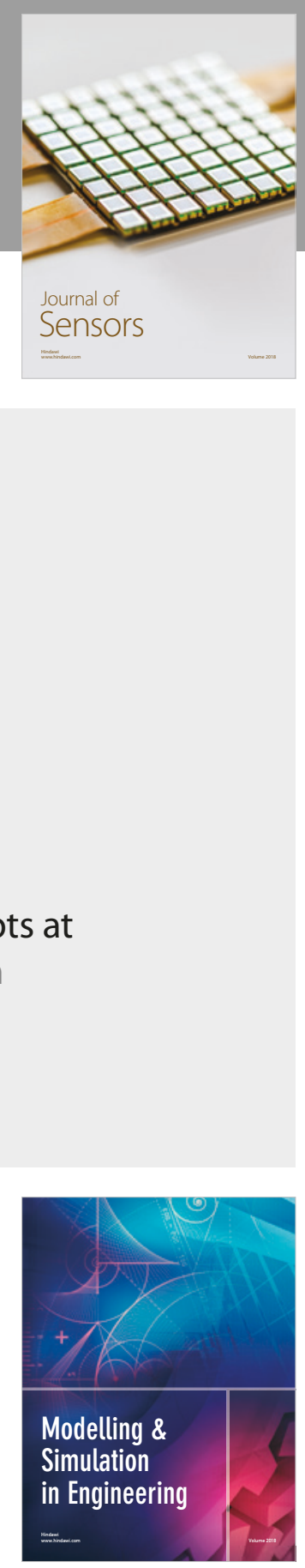

\section{Advances \\ Multimedia}
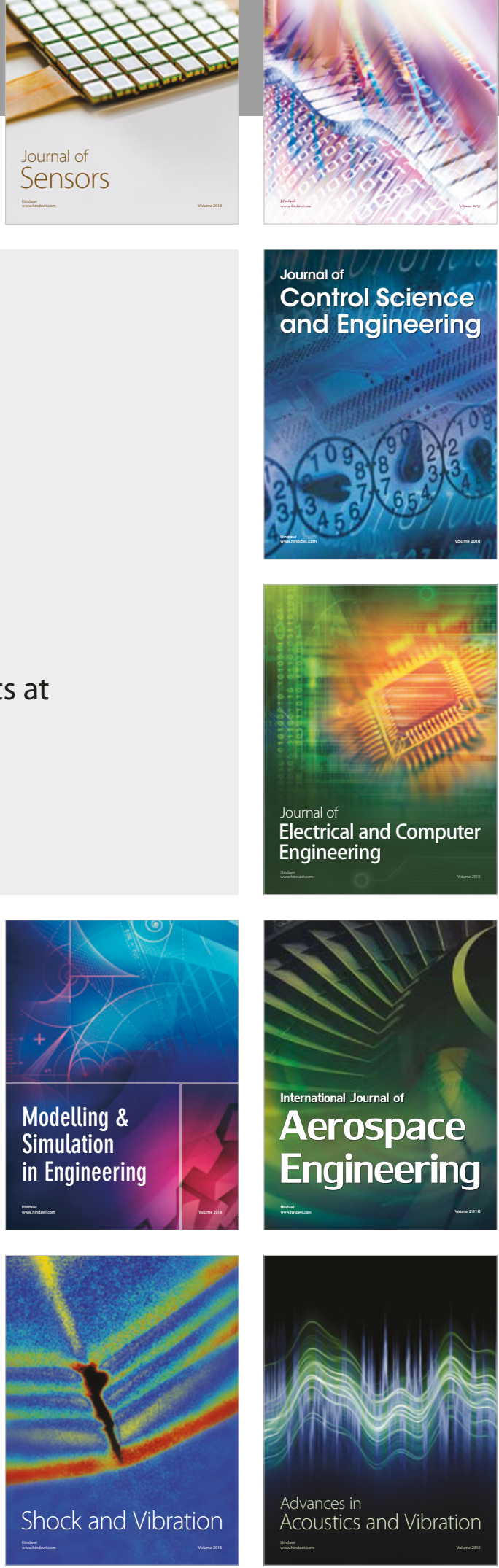